\title{
LARYNGOLOGY
}

\section{The thyro-cricoarytenoid space (TCAS): clinical and prognostic implications in laryngeal cancer}

\author{
Lo spazio tiro-crico-aritenoideo (TCAS): implicazioni cliniche e prognostiche \\ nel carcinoma laringeo
}

\author{
Marco Lucioni', Marco Lionello', Francesco Guida², Federica Sovran³, Fabio Canal ${ }^{4}$, Giuseppe Rizzotto ${ }^{1}$, Andy Bertolin \\ ${ }^{1}$ Otolaryngology Unit, Vittorio Veneto Hospital, Italy; ${ }^{2}$ Department of Otorhinolaryngology and Head and Neck Surgery, Trieste \\ University Hospital - ASUITS, Trieste, Italy; ${ }^{3}$ Radiology Unit, Vittorio Veneto Hospital, Italy; ${ }^{4}$ Pathology Unit, Vittorio Veneto - \\ Conegliano Hospital, Italy
}

\begin{abstract}
SUMMARY
The recent literature on laryngeal surgical oncology has increasingly focused on the negative prognostic impact of neoplastic involvement of the posterior portion of the inferior paraglottic space, which we refer to as the "thyro-cricoarytenoid space" (TCAS). We retrospectively considered the prognostic significance of TCAS involvement in a cohort of 84 patients treated with open partial horizontal laryngectomy for glottic squamous cell carcinoma. Univariate analysis was conducted on the prognostic value of several clinical and pathological parameters. Cases with TCAS involvement experienced a higher recurrence rate and shorter disease-free survival. Neoplasms involving the TCAS should be considered and treated as extralaryngeal malignancies. Posterior glottic tumours with TCAS invasion have worse prognosis when managed with conservative surgery. Total laryngectomy should be considered in cases of locally-advanced glottic carcinoma with TCAS involvement.
\end{abstract}

KEY WORDS: TCAS, thyrocricoarytenoid, space, posterior, glottic carcinoma

\section{RIASSUNTO}

La recente letteratura riguardante la chirurgia oncologica laringea si sta sempre più focalizzando sul significato prognostico negativo del coinvolgimento da parte della neoplasia della porzione posteriore dello spazio paraglottico inferiore, che può essere definito spazio "tiro-crico-aritenoideo" (TCAS). Abbiamo valutato retrospettivamente il significato prognostico del coinvolgimento di tale sito anatomico in una coorte di 84 pazienti trattati con laringectomia parziale orizzontale open. $\grave{E}$ stato inoltre valutato mediante analisi univariata il significato prognostico dei parametri clinici e patologici. I casi con coinvolgimento del TCAS hanno avuto un maggior tasso di recidiva ed una minore sopravvivenza libera da malattia, rispetto ai casi senza coinvolgimento dello stesso. In conclusione, le neoplasie coinvolgenti questo sito laringeo dovrebbero essere considerate e trattate come tumori extra-laringei. I carcinomi glottici posteriori con invasione del TCAS hanno una prognosi peggiore quando gestiti mediante chirurgia conservativa. Nei casi di carcinoma glottico localmente avanzato con coinvolgimento del TCAS la laringectomia totale dovrebbe essere considerata il trattamento di scelta.

PAROLE CHIAVE: TCAS, tirocricoaritenoideo, spazio, posteriore, carcinoma glottico

\section{Introduction}

The recent literature in the sphere of laryngeal surgical oncology has increasingly focused on the anatomical space delineated by the thyroid, cricoid and arytenoid cartilages ${ }^{1-7}$, which we refer to as the "thyro-cricoarytenoid space" (TCAS).

The inferior paraglottic space (PGS) is a submucosal compartment bound laterally by the laryngeal cartilaginous framework and medially by the
Received: June 27, 2019

Accepted: September 10, 2019

Correspondence

Marco Lionello

Otolaryngology Unit, Vittorio Veneto Hospital, via

Forlanini 71, 31029 Vittorio Veneto (TV), Italy

E-mail: marcolionello@email.it

Funding

None.

Conflict of interest

The Authors declare no conflict of interest.

How to cite this article: Lucioni M, Lionello M, Gui-
da F, et al. The thyro-cricoarytenoid space (TCAS):
clinical and prognostic implications in laryngeal
cancer. Acta Otorhinolaryngol Ital 2020;40:106-112.
https://doi.org/10.14639/0392-100X-N0373

( ) Società Italiana di Otorinolaringoiatria e Chirurgia Cervico-Facciale

\section{(c) (1) () $)$}

This is an open access article distributed in accordance with the CC-BY-NC-ND (Creative Commons Attribution-NonCommercial-NoDerivatives 4.0 International) license. The article can be used by giving appropriate credit and mentioning the license, but only for non-commercial purposes and only in the original version. For further information: https:// creativecommons.org/licenses/by-nc-nd/4.0/deed.en 
vocal muscle ${ }^{8}$. We use the acronym TCAS to define the anatomical site that includes the posterior portion of the inferior PGS and adjacent muscles, located dorsally to a coronal plane and lying tangential to the vocal process of the arytenoid cartilages. It is limited laterally by the thyroid lamina and pyriform sinus, and medially by the arytenoid and cricoarytenoid joint (CAJ), as well as by the ipsilateral hemicricoid. Caudally, it borders on the cricoid and the lower edge of the thyroid lamina (Fig. 1). The TCAS consists of adipose tissue, glands and vessels, and contains the thyro-arytenoid and the lateral cricoarytenoid muscles. The lateral cricothyroid muscle identifies a side boundary. Endoscopically, TCAS involvement by a tumour may cause impaired motility or fixation of the vocal cord and arytenoid due to infiltration of the vocal muscle, the lateral cricoarytenoid muscle extending from the arytenoid cartilage, or the $\mathrm{CAJ}^{5,9}$. Contrast-enhanced CT and MRI can reveal direct signs of infiltration, or suspected infiltration, such as sclerosis of the arytenoid ${ }^{10}$ (Fig. 2).

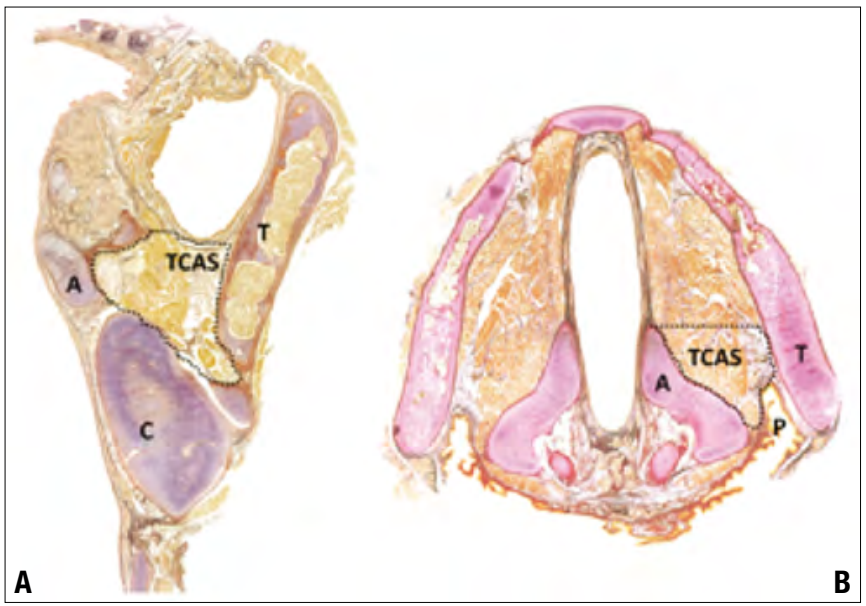

Figure 1. Healthy larynx: coronal (A) and axial (B) histological sections showing the TCAS. A: arytenoid cartilage; C: cricoid cartilage; P: pyriform sinus; T: thyroid cartilage.

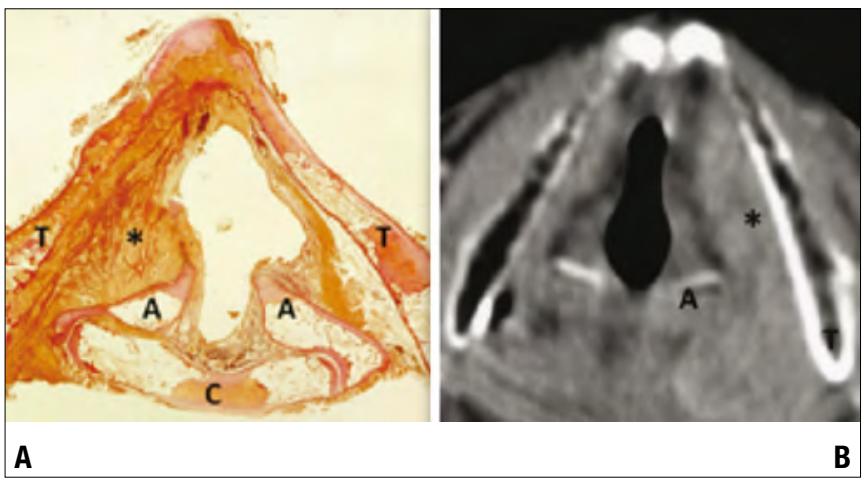

Figure 2. Glottic CT3 carcinoma involving the left TCAS: (A) axial histological section; (B) axial contrast-enhanced CT scan. A: arytenoid cartilage; C: cricoid cartilage; T: thyroid cartilage; ${ }^{*}$ : tumour.
The TCAS is always involved when laryngeal cancer spreads posteriorly through the PGS, and this event coincides with dramatically worsening prognosis ${ }^{5}$.

The primary aim of the present study was to retrospectively investigate the prognostic meaning of TCAS involvement by laryngeal squamous cell carcinoma (LSCC) treated with open partial horizontal laryngectomy (OPHL).

\section{Methods}

\section{Patients}

From 2013 to 2016, 106 patients consecutively underwent OPHL at the Otolaryngology Service of Vittorio Veneto Hospital (Italy). The present study involved a cohort of 84 LSCC patients (67 men and 17 women; mean age $60.1 \pm 9.4$ years, median 63) who met the inclusion criteria.

Exclusion criteria were: i) supraglottic cancer treated with supraglottic laryngectomy (OPHL I), since the primary aim of our study was to examine the posterior portion of the inferior PGS; ii) patients who underwent salvage OPHL; iii) a follow-up $<24$ months; iv) locally-advanced disease making it impossible to establish the anterior vs posterior compartmentalisation of the tumour; v) final histology other than LSCC.

Clinical charts were retrospectively reviewed and any radiological/pathological evidence of TCAS involvement was recorded.

Laryngeal tumours were staged according to the $8^{\text {th }}$ classification of the Union Internationale Contre le Cancer and the American Joint Committee on Cancer.

All patients completed preoperative diagnostic workup with laryngeal indirect flexible video-endoscopy, contrast-enhanced neck CT scan or MRI, chest X-ray, and oesophagoscopy. In all cases, TCAS involvement was preoperatively evaluated with contrast enhanced CT scans or MRI of the larynx. Laryngoscopy was then performed under general anaesthesia using rigid $0^{\circ}, 30^{\circ}$ and $70^{\circ}$ telescopes in white light and narrow band imaging to complete the diagnostic work-up.

All procedures performed were in accordance with the ethical standards of the institutional Ethics Review Board and with the 1964 Helsinki declaration and its later amendments or comparable ethical standards.

\section{Surgery}

An OPHL was adopted in selected cases of early glottic cancer (cT1-2) not amenable to transoral laser microsurgery (TLM), and selected cases of intermediate or advanced disease (cT3-4a), with at least one safe cricoarytenoid unit, 
no massive extralaryngeal spread (i.e. a limited diffusion to prelaryngeal tissues without invasion of the thyroid gland or of the infrahyoid muscles), and acceptable general conditions and comorbidities. General patient-related contraindications to OPHL included alcohol and drug abuse, or major comorbidities such as heart failure, lung diseases, mellitus diabetes, or severe neurocognitive decay. The open partial procedures consisted of supracricoid laryngectomy with cricohyoidoepiglottopexy (OPHL type IIa), or cricohyoidopexy (OPHL type IIb), and supratracheal laryngectomy with tracheohyoidoepiglottopexy (OPHL type IIIa), or tracheohyoidopexy (OPHL type IIIb), according to the ELS classification.

Pathological examination of the surgical margins was routinely performed on intraoperative frozen sections during OPHL. All margins were also checked postoperatively by final histology.

A radical or modified radical neck dissection (RND and MRND, respectively) were performed in the event of clinically or radiologically proven lymph node involvement. Selective neck dissection (SND) of levels IIIII-IV was performed electively for cT3-4a N0 disease, or with curative intent for clinically or radiologically limited node metastases. Bilateral neck dissection was routinely performed in cases of supraglottic spread. An ipsilateral paratracheal neck dissection was used in the event of disease extending to the hypoglottis.

\section{Pathological assessment}

All laryngectomy specimens were opened postoperatively, and analysed for tumour site and extent. All sections were examined by the same team of experienced head and neck pathologists. Slides stained with haematoxylin and eosin, and photographs of gross specimens were reviewed and assessed in terms of TCAS involvement. All examinations were performed at $\times 1, \times 5, \times 10, \times 20$, and $\times 40$ magnification with a Leica DM LB microscope (Meyer Instruments, Inc., Houston, TX) connected to a personal computer. For each case, 2 to 10 full-length longitudinal sections containing the tumour were obtained, depending on the tumour's size.

\section{Statistical analysis}

Fisher's exact test was used to calculate the association between different clinical and pathological parameters and the disease recurrence rate. The log-rank test and KaplanMeier survival function were used to calculate diseasefree survival (DFS) for patients stratified by the selected variables.

The multivariate logistic model (Wald test) was applied to the same parameters (Fisher's exact test, $\mathrm{p}<0.20$ ) to identify independent prognostic factors in relation to recurrence rate, and the relative $95 \%$ confidence intervals were calculated. A p-value $<0.05$ was considered significant. The STATA 14 statistical package (Stata Corp., College Station, TX) was used for all analyses.

\section{Results}

\section{Open partial horizontal laryngectomies}

OPHL type IIa was performed in 46 cases, type IIb in 3, and type IIIa in 35; none of the patients had OPHL type IIIb. Eighteen patients $(21 \%)$ experienced disease recurrence after $13.8 \pm 10.6$ months.

The cases of LSCC were classified as follows: cT1 in 1 patient; cT2 in 29; cT3 in 47; and cT4a in 7. Regional node status was classified as: cN0 in 68 cases; cN1 in 5; $\mathrm{cN} 2$ in 10; and $\mathrm{cN} 3$ in one. The pathological classification was: pT1 in 3 cases; pT2 in 10; pT3 in 52; and pT4a in 19. The pathological classification of cervical nodes was: pNX-0 in 69 cases; $\mathrm{pN} 1$ in 3; pN2 in 3 ; and $\mathrm{pN} 3$ in 9 .

Ipsilateral neck dissection was performed in 70 cases, and bilateral neck dissection in 11. There was evidence of extranodal dissemination in 11 cases. Twenty-seven patients received postoperative radiotherapy or chemoradiotherapy $(\mathrm{CRT})$.

\section{Pathological findings}

In 49 cases, the tumour involved the posterior glottis with TCAS invasion, while in 35 cases the TCAS was uninvolved. Table I shows the distribution of the main pathological findings by presence or absence of TCAS invasion.

At pathology, 27 patients had positive surgical margins, while 57 had free or close surgical margins. Vascular and perineural invasion were detected in 43 and 27 cases, respectively. As for pathological grade, this was well differentiated in 19 cases, moderately differentiated in 33, poorly differentiated in 22 and indeterminate in 10.

Table I. Main pathological findings in patients with or without TCAS invasion.

\begin{tabular}{lccc} 
& $\begin{array}{c}\text { TCAS invasion } \\
\text { (No. of patients) }\end{array}$ & $\begin{array}{c}\text { No TCAS invasion } \\
\text { (No. of patients) }\end{array}$ & $\mathbf{p}^{*}$ \\
pN+ & 6 & 7 & 0.92 \\
Vascular invasion & 24 & 19 & 0.68 \\
Perinerural invasion & 15 & 11 & 0.75 \\
Delphic node metastasis & 2 & 0 & 0.75 \\
Extranodal extension & 6 & 5 & 0.82 \\
Positive margins & 15 & 12 & 0.77 \\
Total & 49 & 35 & \\
\hline
\end{tabular}

*: Mann-Whitney U-test. 


\section{Oncological outcomes}

The mean follow-up was 50.1 \pm 44.5 months (range 26-71 months). Seven patients were lost to follow-up. At latest follow-up, 70 patients (82\%) were alive and disease-free, $10(12 \%)$ were alive with disease, $2(3 \%)$ died of their disease and $2(3 \%)$ died with no evidence of disease. The final overall and disease-specific survival rates were $95 \%$ and $97 \%$, respectively. Considering only cases with TCAS involvement, 15 patients experienced disease recurrence, and 2 died of their disease. Among the patients with no TCAS invasion, 3 suffered a relapse, 2 died of other causes and none died of their LSCC.

\section{Univariate and multivariate analysis}

Details of the results of univariate analysis are shown in Table II. Higher recurrence rates and shorter DFS rates were seen in patients with TCAS invasion, those who underwent OPHL III, and those with younger age (Fig. 3), although no significant $p$ values emerged from our statistical analyses. Patients with locally intermediate or advanced disease (pT3-4) and positive nodes ( $\mathrm{pN}+$ ) had a higher recurrence rate and shorter DFS (Fig. 3), although statistical analysis identified no significant $\mathrm{p}$ values. Patients with positive surgical margins had a significantly higher recurrence rate and shorter DFS (Fig. 3) than those with negative margins.

Multivariate analysis confirmed that only the status of surgical margins was an independent prognostic factor in terms of recurrence rate (Tab. III)

\section{Discussion}

Several recently published reports corroborate the poorer prognosis associated with the posterior spread of glottic

Table II. Recurrence and disease-free survival rates (months) by main clinical and pathological parameters.

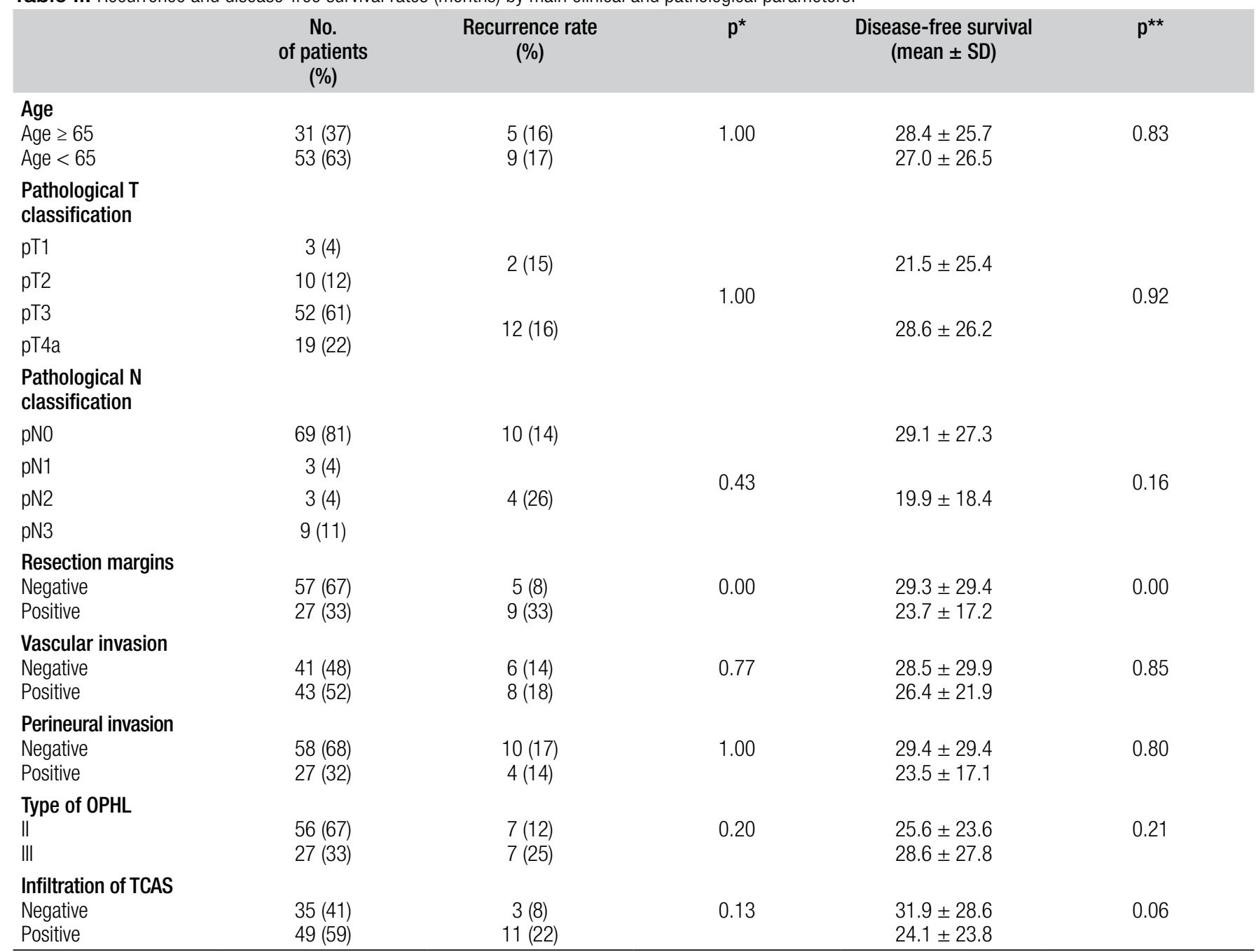

: Fisher's exact test; ${ }^{* *}$ : Log-rank test. 


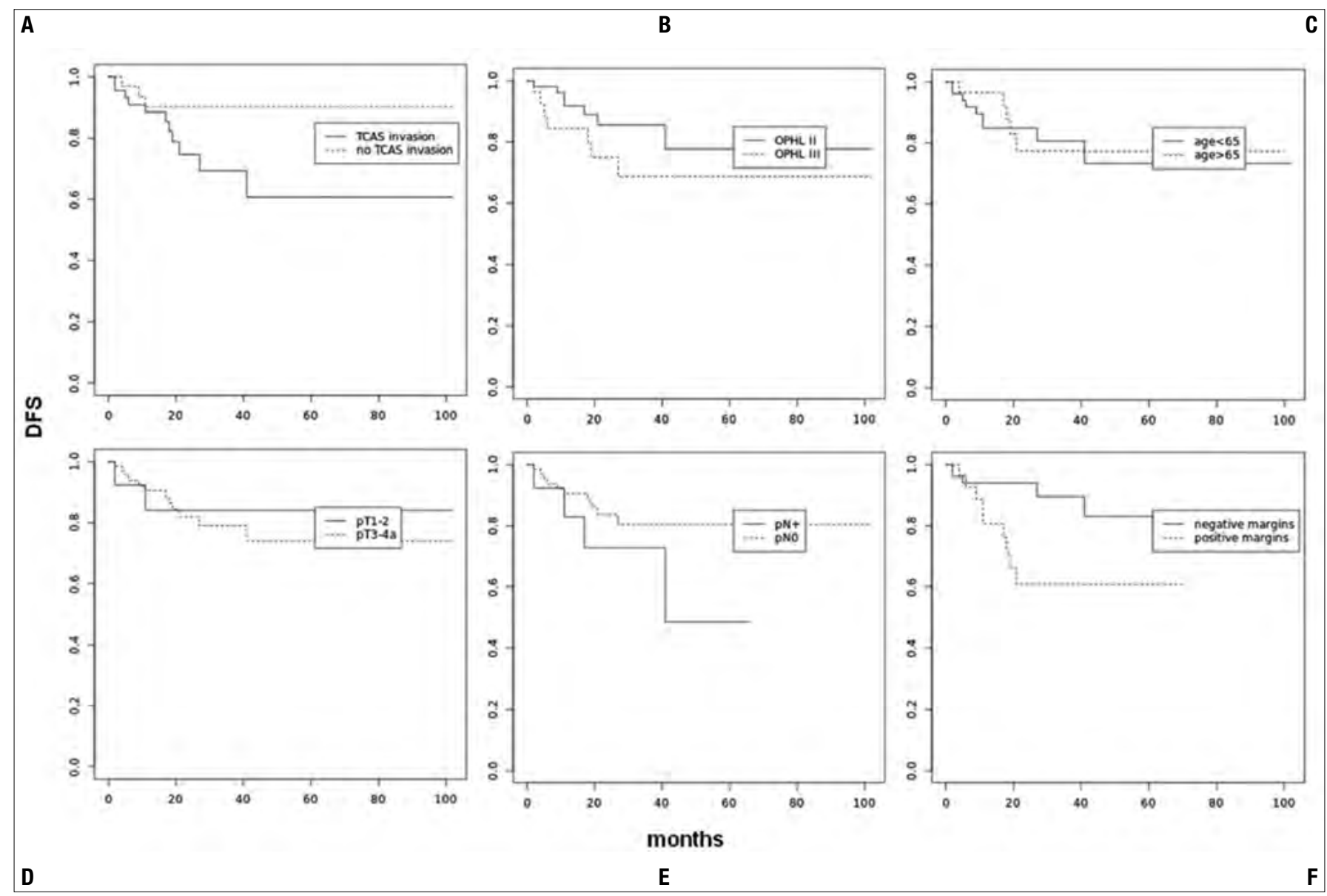

Figure 3. Kaplan Meier disease-free survival curves for patients stratified by TCAS invasion (A); surgical procedure (B); age (C); pT classification (D); pN classification (E); and status of surgical margins (F).

carcinoma. TCAS involvement is a negative prognostic factor for intermediate-advanced glottic carcinomas in terms of locoregional control rates after both surgical and nonsurgical treatments ${ }^{5,7,11,12}$.

Lee and coworkers considered primary radiation treatment with 6-MV photons for the treatment of early glottic cancer, finding that patients with posterior third involvement had a poor local control rate, and suggesting that alternative approaches should be considered ${ }^{12}$.

Using TLM, the deep muscle plane (the lateral cricoarytenoid and cricothyroid muscles) may not be manageable endoscopically with sufficient radicality ${ }^{9}$, and thus TCAS involvement represents a clear contraindication to TLM.

In a cohort of patients with pT3N0 glottic disease and arytenoid fixation treated with OPHL IIa, Luna-Ortiz et al. reported that neoadjuvant chemotherapy produced an oncological benefit in patients awaiting surgery ${ }^{13}$.

In 2018, Succo and coworkers analysed oncological outcomes of OPHL for locally-advanced LSCC by glottic compartmentalisation. The authors distinguished between
pT3 glottic carcinomas that were "anterior" as opposed to "posterior" (subcategories I and II, respectively) to an ideal coronal plane tangential to the vocal process of the arytenoid cartilages. They found that anterior pT3 tumours (subcategory I) had better OS, DSS, DFS and locoregional control rates than posterior pT3 tumours (subcategory II) ${ }^{5}$. Our results confirm these findings, since TCAS invasion correlated with a worse prognosis in terms of recurrence rate and DFS. We might hypothesise an anatomical explanation: while the thyroid lamina is an excellent barrier to the tumour's anterior diffusion, posteriorly it can proceed towards the pyriform sinus, retrocricoid region and through the thyro-cricoid membrane towards the paralaryngeal spaces.

The TCAS serves as the postero-lateral resection margin in OPHL, and preoperative misdiagnosis of tumour spread at this level can be responsible for locally relapsing disease. However, in the present study, statistical analysis failed to recognise a correlation between the status of margins and TCAS invasion $(\mathrm{p}=0.77)$ 
Table III. Multivariate analysis of the main clinical and pathological parameters.

\begin{tabular}{|c|c|c|c|c|}
\hline & Odds ratio & $\mathbf{p}^{*}$ & $\begin{array}{c}95 \% \\
\text { confidence interval }\end{array}$ & $\mathbf{p}^{\star \star}$ \\
\hline $\begin{array}{l}\text { Pathological N classification } \\
\text { pNO } \\
\text { pN+ }\end{array}$ & $\begin{array}{l}1.00 \\
2.25\end{array}$ & 0.43 & $\begin{array}{c}\text { Reference group } \\
0.11-1.22\end{array}$ & 0.35 \\
\hline $\begin{array}{l}\text { Resection margins } \\
\text { Negative } \\
\text { Positive }\end{array}$ & $\begin{array}{l}1.00 \\
3.25\end{array}$ & 0.00 & $\begin{array}{l}\text { Reference group } \\
0.13-0.72\end{array}$ & 0.00 \\
\hline $\begin{array}{l}\text { Type of OPHL } \\
\| \\
\|\|\end{array}$ & $\begin{array}{l}0.95 \\
2.05\end{array}$ & 0.20 & $\begin{array}{c}\text { Reference group } \\
0.95-4.95\end{array}$ & 0.30 \\
\hline $\begin{array}{l}\text { Infiltration of TCAS } \\
\text { Negative } \\
\text { Positive }\end{array}$ & $\begin{array}{l}0.90 \\
2.00\end{array}$ & 0.13 & $\begin{array}{l}\text { Reference group } \\
0.62-4.80\end{array}$ & 0.10 \\
\hline
\end{tabular}

*: Fisher's exact test; **: Wald test.

(Tab. I). On the other hand, if independently considered, these two parameters were related to worsening of the oncologic outcome, in terms of recurrence rate and DFS. We hypothesised that this finding could be related to lymphatic neoplastic embolisation, which, due to the anatomical peculiarity, is more likely to interest the posterior rather than the anterior glottis.

When the tumour infiltrates the TCAS, conservative surgery should very carefully be considered. The tumour's contiguity to the CAJ often means that the cricoarytenoid unit has to be sacrificed. Supratracheal laryngectomy (OPHL type III) thus becomes the only available conservative surgical approach in cases of TCAS involvement, but local control is unsatisfactory ${ }^{5}$. Such cases should be managed with total laryngectomy.

The literature also provides evidence to suggest that carcinoma spreading to the posterior glottis from the various primary laryngeal and pyriform fossa sites may follow differing pathways of invasion, but always reveals a direct extension and connection to the subglottis ${ }^{14}$.

Given the absence of anatomical barriers, the tumour can spread through the TCAS into the retrocricoid region (hypopharynx) and extralaryngeal neck compartment. Invasion of the fibres of the previously mentioned intralaryngeal muscles could represent a preferential pathway for the spread of tumour cells. Given the higher concentration of lymphatic vessels in the PGS than in the vocal cord, neoplastic involvement of the TCAS could also prompt early diffusion of tumour cells into the lateral and paratracheal neck regions, increasing the risk of neck metastases.

In 2018, Lucioni and coworkers investigated paratracheal lymph node involvement in LSCC extending into the subglottis. They found a significant correlation between paratracheal and laterocervical lymph node involvement in patients with posterior subglottic extension ${ }^{15}$.
In a previously mentioned study, Succo et al. found tumours with a posterior glottic localisation were at higher risk of neck metastases to both the laterocervical and anterior levels (OR 1.69, and 3.77, respectively). The rate of node metastases with extracapsular dissemination was also significantly higher in posterior than in anterior pT3 glottic carcinomas (OR 2.03) ${ }^{5}$.

Tumour invasion of the TCAS can significantly impair vocal cord motility due to a more limited arytenoid mobility, or to complete fixation of the vocal cord as a result of invasion of the crico-arytenoid muscles or cricoarytenoid joint. In a recently published study, our group investigated the clinical and radiological signs of posterior glottic tumour dissemination (through the TCAS). We found that it significantly related to impaired vocal cord motility and radiological evidence of sclerosis of the arytenoid cartilage ${ }^{4}$. The recent literature confirmed the negative prognostic meaning of such posterior spread of glottic cancer to the cricoarytenoid joint and associated arytenoid fixation ${ }^{6}$. A change of TNM classification (from T3 to T3b) have already been suggested as a result ${ }^{1}$. Involvement of the cricoarytenoid joint, with fixation of the arytenoid, would preclude many conservative laryngeal surgical approaches ${ }^{1}$.

\section{Conclusions}

The TCAS is a critical issue in the case of laryngeal cancer dissemination, and neoplasms involving this site should be considered and treated as extralaryngeal malignancies. Posterior glottic tumours with TCAS invasion have poorer prognosis when managed with conservative surgery or CRT. Given the poor oncological results, TLM should be avoided in such cases, and the feasibility of OPHL should also be carefully assessed. 


\section{Acknowledgements}

The authors thank Frances Coburn for correcting the English version of this paper. They also thank all the medical and paramedical staff at the Otolaryngology Unit - Vittorio Veneto Hospital, for collecting the follow-up data, and the Association "Amici della voce" (Friends of the Voice) for support in preparing the manuscript.

\section{References}

1 Holsinger FC, Diaz EM Jr. Laryngeal preservation in the era of chemoradiation: limitations of the current AJCC staging system. Head Neck 2006;28:1058-60. https://doi.org/10.1002/hed.20499

2 Beitler JJ, Muller S, Grist WJ, et al. Prognostic accuracy of computed tomography findings for patients with laryngeal cancer undergoing laryngectomy. J Clin Oncol 2010;28:2318-22. https://doi. org/10.1200/JCO.2009.24.7544

3 Atilmis H, Ozturkcan S, Ozdemir I, et al. A clinicopathological study of laryngeal and hypopharyngeal carcinoma: correlation of cord-arytenoid mobility with histopathologic involvement. Otolaryngol Head Neck Surg 2007;136:291-5. https://doi.org/10.1016/j. otohns.2006.08.022

4 Lucioni M, Lionello M, Machin P, et al. Sclerosis of the arytenoid cartilage and glottic carcinoma: a clinical-pathological study. Head Neck 2019;41:72-8. https://doi.org/10.1002/hed.25372

5 Succo G, Crosetti E, Bertolin A, et al. Treatment for T3 to T4a laryngeal cancer by open partial horizontal laryngectomies: prognostic impact of different pathologic tumor subcategories. Head Neck 2018;40:1897-908. https://doi.org/10.1002/hed.25176

6 Succo G, Cirillo S, Bertotto I, et al. Arytenoid fixation in laryngeal cancer: radiological pictures and clinical correlations with respect to conservative treatments. Cancers (Basel) 2019;11:360. https://doi. org/10.3390/cancers 11030360

7 Del Bon F, Piazza C, Lancini D, et al. Open partial horizontal laryngectomies for T3-T4 laryngeal cancer: prognostic impact of anterior vs. posterior laryngeal compartmentalization. Cancers (Basel) 2019;11:289. https://doi.org/10.3390/cancers11030289

8 Lucioni M. Practical guide to neck dissection. Focusing on the larynx. Second Edition. Heidelberg: Springer; 2013.

9 Peretti G, Piazza C, Mora F, et al. Reasonable limits for transoral laser microsurgery in laryngeal cancer. Curr Opin Otolaryngol Head Neck Surg 2016;24:135-9. https://doi.org/10.1097/ MOO.0000000000000240

10 Ravanelli M, Paderno A, Del Bon F, et al. Prediction of posterior paraglottic space and cricoarytenoid unit involvement in endoscopically $\mathrm{T} 3$ glottic cancer with arytenoid fixation by magnetic resonance with surface coils. Cancers (Basel) 2019;11:67. https://doi. org/10.3390/cancers 11010067

11 Solares CA, Wood B, Rodriguez CP, et al. Does vocal cord fixation preclude nonsurgical management of laryngeal cancer? Laryngoscope 2009;119:1130-4. https://doi.org/10.1002/lary.20225

12 Lee JH, Machtay M, McKenna MG, et al. Radiotherapy with 6-megavolt photons for early glottic carcinoma: potential impact of extension to the posterior vocal cord. Am J Otolaryngol 2001;22:4354. https://doi.org/10.1053/ajot.2001.20679

13 Luna-Oritz K, Villavicencio-Valencia V, Rodriguez-Falconi A, et al. Induction chemotherapy followed by supracricoid partial laryngectomy (SCPL) with cricohyoidoepiglottopexy (CHEP) in T3NO arytenoid fixation-related glottic cancer. B-ENT 2016;12:271-7.

14 McIlwain JC. The posterior glottis. J Otolaryngol 1991;20(Suppl 2):1-24.

15 Lucioni M, D'Ascanio L, De Nardi E, et al. Management of paratracheal lymph nodes in laryngeal cancer with subglottic involvement. Head Neck 2018;40:24-33. https://doi.org/10.1002/hed.24905 